\title{
APROVEITAMENTO DE ÁGUA DA CHUVA PARA FINS NÃO POTÁVEIS COMO ALTERNATIVA DE MELHORIA DA ATUAL SITUAÇÃO DOS RECURSOS HÍDRICOS
}

Karla Karoline Leite do Rosário - karlaleite93@ gmail.com Universidade do Estado do Pará

Danielle de Lima Farias - danielle.ambiental@ hotmail.com

Universidade do Estado do Pará

Juliane da Costa Cavalcante - julianecosta63@ gmail.com

Universidade do Estado do Pará

Mateus Souza Morais - mateussmorais8@gmail.com

Universidade do Estado do Pará 


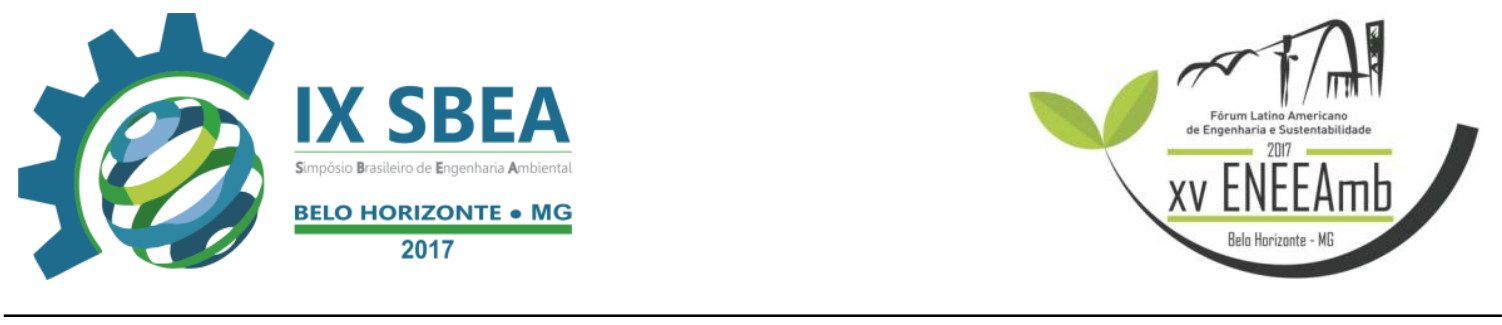

\section{RESUMO}

O atual cenário de crescimento e desenvolvimento do planeta, colocam em destaque questões sobre a conservação dos recursos hídricos. As técnicas de aproveitamento de água da chuva são soluções sustentáveis que estão sendo cada vez mais procuradas, contribuindo para o uso racional da água e auxiliando na sua conservação. Objetivou-se através deste estudo discutir sobre a técnica de aproveitamento da água da chuva como alternativa para a sua carência em determinadas regiões. Foram realizados levantamentos bibliográficos visando identificar a situação atual desse recurso. Os resultados demonstram um quantitativo pluvial satisfatório para o seu aproveitamento em fins não potáveis.

Palavras-chave: Aproveitamento, Água da chuva, Recursos Hídricos.

\section{INTRODUÇÃO/OBJETIVO}

O atual cenário do planeta, de crescimento da população, da economia e, consequentemente, da poluição, acabam se tornando um alerta para uma possível crise no abastecimento e na qualidade de água no mundo inteiro (OLIVEIRA et al., 2014). Assim, o mais importante recurso a ser preservado, levando-se em consideração a dependência para a manutenção da vida dos seres vivos e das atividades econômicas, é a água.

Práticas e técnicas para o reaproveitamento de água acabam por auxiliar na manutenção desse recurso esgotável. Nesse contexto, o artigo tem como objetivo discutir sobre a técnica de aproveitamento da água da chuva para fins não potáveis, por meio de revisão bibliográfica, como alternativa para suprir a falta de água ocasionada pela escassez em algumas regiões, e por uma gestão e distribuição ineficientes.

\section{METODOLOGIA}

Para tal objetivo foi realizado levantamentos bibliográficos visando identificar a situação atual dos Recursos Hídricos, além de métodos para o aproveitamento da água da chuva. A metodologia é de caráter exploratória realizada por meio de levantamento bibliográfico. 


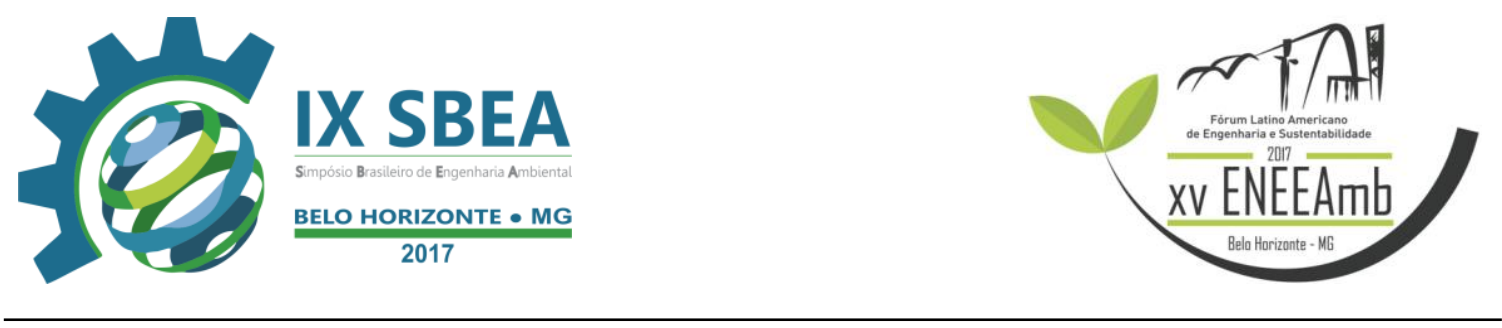

\section{RESULTADOS E DISCUSSÃO}

\section{Disponibilidade e demanda de Recursos hídricos}

A grande demanda de água, para a manutenção da vida na terra e das diversas atividades antrópicas ressalta ainda mais a importância de estudos voltados para a gestão desse recurso. Principalmente em relação a um gerenciamento que atenda aos seus usos múltiplos, tendo uma boa relação entre disponibilidade e demanda.

No território brasileiro passam em média cerca de $260.000 \mathrm{~m}^{3} / \mathrm{s}$ de água, dos quais $205.000 \mathrm{~m}$ 3/s estão localizados na bacia do rio Amazonas, restando para o restante do território $55.000 \mathrm{~m}^{3} / \mathrm{s}$ de vazão média. No país, a disponibilidade hídrica é em torno de $12.000 \mathrm{~m}^{3} / \mathrm{s}$ (ANA, 2016).

De acordo com dados da Agência Nacional de Água (2016), para o ano de 2015 a vazão consultiva total estimada para o Brasil foi de $2.275,07 \mathrm{~m}^{3} / \mathrm{s}$. Sendo que a vazão efetivamente consumida foi de $1.209,64 \mathrm{~m}^{3} / \mathrm{s}$, ou seja, grande parte volta como efluente para o sistema de drenagem, sendo muitas vezes não tratado. Da vazão de retirada $22 \%$ são destinados ao abastecimento urbano.

Sendo a água um recurso esgotável, deve-se também levar em consideração que a sociedade está enfrentando um grande crescimento populacional, assim como das diversas formas de poluição, provocando uma crise no abastecimento de água potável, onde grande parte da reserva de água doce do planeta se encontra poluída ou ameaça pela poluição, principalmente em centros urbanos (OLIVEIRA et al., 2014).

Pela falta de investimento e uma gestão de recursos hídricos efetiva muitas populações acabam não sendo atendidas pelo sistema de abastecimento de água potável. A região metropolitana de Belém é composta por cinco municípios que concentram 1/3 da população estadual. Mesmo com a grande demanda $30 \%$ dessa população não é beneficiada com água tratada (ANA, 2016).

De acordo com Vasconcelos (2007), a possibilidade do uso de água da chuva para usos básicos em residências certamente resultará na diminuição do uso de água fornecida pelas companhias de saneamento e na demanda dos custos do uso de água potável. Sendo uma alternativa viável para suprir em parte a má distribuição e/ou escassez desse recurso em determinadas localidades. 


\section{Política de Recursos Hídricos}

Existe um projeto de lei (PL no 7.818/2014) em nível federal para criação da Política Nacional de Captação, Armazenamento e Aproveitamento de Águas Pluviais. No entanto, ainda não existe legislação que regulamente e crie diretrizes para o aproveitamento de água de chuva em todo território brasileiro (CARTILHA APROVEITAMENTO DE ÁGUA PLUVIAL, 2017).

A Política Nacional de Recursos Hídricos, Lei $n^{\circ}$ 9.433, de 8 de janeiro de 1997, não aborda de maneira explicita acerca do aproveitamento da água da chuva, todavia em suas entrelinhas é possível notar diversas possibilidades de uso.

Inicialmente a PNRH dispõe seus fundamentos, dos quais pode-se destacar o inciso VI - "a gestão dos recursos hídricos deve ser descentralizada e contar com a participação do Poder Público, dos usuários e das comunidades." - isto viabiliza a participação de todos na gestão de recursos hídricos, desde a utilização de sistemas caseiros de captação de água da chuva até os mais elaborados, de grande porte.

Os objetivos da Política Nacional em questão, de maneira sucinta, almejam: assegurar à atual e às futuras gerações a necessária disponibilidade de água, a utilização racional e integrada dos recursos hídricos, a prevenção e a defesa contra eventos hidrológicos críticos de origem natural ou decorrentes do uso inadequado dos recursos naturais; com isto é notório que apesar de não abordar como alternativa o uso das águas pluviais, a Política visa o desenvolvimento sustentável, ou seja, a existência de recursos hídricos em quantidade e qualidade para as futuras gerações.

A Política de Recursos Hídricos do Estado do Pará, Lei no 6.381, de 25 de julho de 2001, assemelha-se a Nacional em seus fundamentos e objetivos, assim como em suas diretrizes. Contudo as diretrizes do Estado contemplam mais as especificidades locais, por exemplo: a execução e manutenção de campanhas educativas visando à conscientização da sociedade para a utilização racional dos recursos hídricos; e o Estado articular-se-á com a União, Estados vizinhos e Municípios, visando à atuação conjunta para o aproveitamento e controle dos recursos hídricos e respectivos impactos em seu território - e nestas é mostrada a necessidade de conscientização da sociedade, bem como a articulação das esferas de gestão. 
O aproveitamento de águas da chuva é uma medida sustentável, de alta viabilidade, desde pequenos à grandes sistemas de captação, porém não é abordado explicitamente na Política Nacional e Estadual (Pará) de Recursos Hídricos, o que torna de extrema necessidade a criação de uma legislação específica que regulamente esta atividade.

\section{Aproveitamento de Água da Chuva}

O Brasil é um país de grande extensão territorial, localizado na América do Sul, possui seis tipos de clima, com predominância do tropical. Suas reservas de água potável estão diminuindo devido ao crescente consumo, desperdício, poluição das águas superficiais e subterrâneas sendo atingidos por esgotos domésticos, resíduos tóxicos da indústria e da agricultura. Seu vasto território está dividido em cinco regiões, definidas por critérios de semelhanças físicas, humanas, culturais e econômicas. (IBGE, 2016).

Em condições de escassez, a população e os órgãos gestores buscam fontes alternativas de água para o desenvolvimento pleno das atividades humanas. Dentre elas, destaca-se a água de chuva que pode ser facilmente armazenada e preservada para uso nas épocas de estiagens. (FUNASA, 2007)

Tabela 1- Proporção de área territorial, disponibilidade da água e população para as cinco regiões do Brasil.

\begin{tabular}{|c|c|c|c|}
\multicolumn{1}{|c|}{$\begin{array}{c}\text { Região do } \\
\text { Brasil }\end{array}$} & $\begin{array}{c}\text { Área } \\
\text { Territorial } \\
(\%)\end{array}$ & $\begin{array}{c}\text { Disponibili } \\
\text { dade de Água (\%) }\end{array}$ & $\begin{array}{l}\text { População } \\
(\%)\end{array}$ \\
\hline Norte & 45 & 69 & 8 \\
\hline Nordeste & 18 & 3 & 28 \\
\hline Sudeste & 11 & 6 & 43 \\
\hline Sul & 7 & 6 & 15 \\
\hline Centro- & 19 & 15 & 7 \\
\hline
\end{tabular}

Fonte: GHISI, 2006, adaptado. 


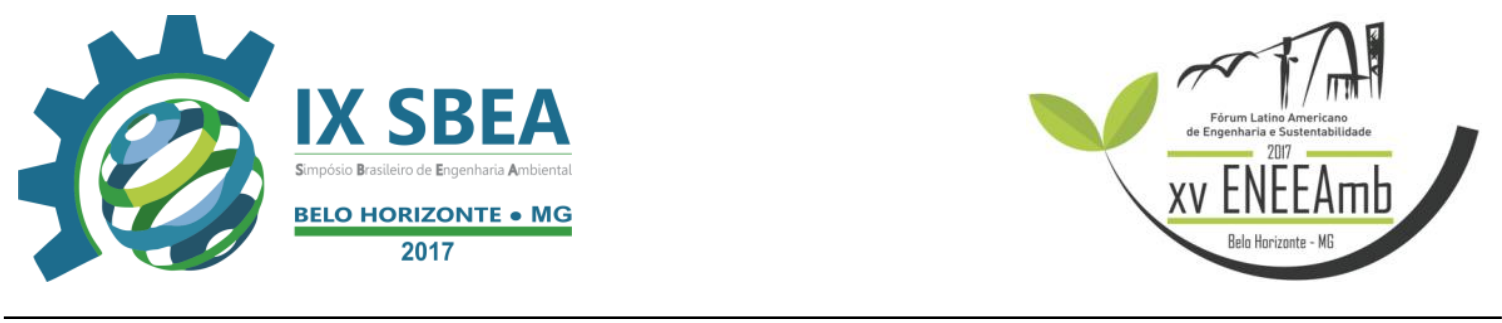

Apesar da riqueza em recursos hídricos da região Amazônica, a cidade de Belém é grande deficitária em abastecimento público de água. Por conta dessa dificuldade de saneamento, existem estudos que visam o aproveitamento da água da chuva na Amazônia visando identificar com segurança os volumes disponíveis que atendam a demanda, assim há dois estudos que contribuem para o trabalho em questão: o trabalho de LIMA et al (2011) e de SOUZA et al (2012).

Aplicando o método de Ghisi et al. (2006), que consiste em (a) definir a disponibilidade de água pluvial na cidade; (b) identificar a infraestrutura de captação nos domicílios; e (c) definir a demanda com algumas especificações para a Região, tais como: cálculos de pluviosidade, captação e demanda, que foram aplicados por Lima et al. (2011) onde estudaram a porção Ocidental da Amazônia, o que envolveu 40 cidades situadas nos estados do Amazonas, de Rondônia, do Acre e de Roraima. Na base dos estudos, está a necessidade de identificar a disponibilidade da demanda por água. Foram então usados os dados de precipitação, populações atendidas por serviço de abastecimento de água consomem de água potável, população, número de domicílios e porcentagem de casas e apartamentos.

Então, usam-se os dados de volumes e distribuição da precipitação ao longo do ano. Para a demanda, consideraram o número de pessoas atendidas pelo sistema de abastecimento. Nesse contexto, foi considerado o número de pessoas por domicílio e o número de domicílios abastecidos pelo serviço de água. A partir disso, é preciso identificar a área dos telhados, pois essa é a base para calcular a volume de chuvas possível de ser captada (Lima et al., 2011).

Assim, o potencial de economia de água potável das 40 cidades pesquisadas na Amazônia Ocidental pode ser definido pela Equação (1):

\section{$P P W S=100$ VR/PWE}

em que PPWS é o potencial de economia de água potável em cada cidade (\%); PWE é consumo de água potável mensal em cada cidade ( $\left.\mathrm{m}^{3} / \mathrm{mês}\right)$; e VR é o volume mensal de chuva que poderia ser coletado em cada cidade ( $\left.\mathrm{m}^{3} / \mathrm{mês}\right)$. 


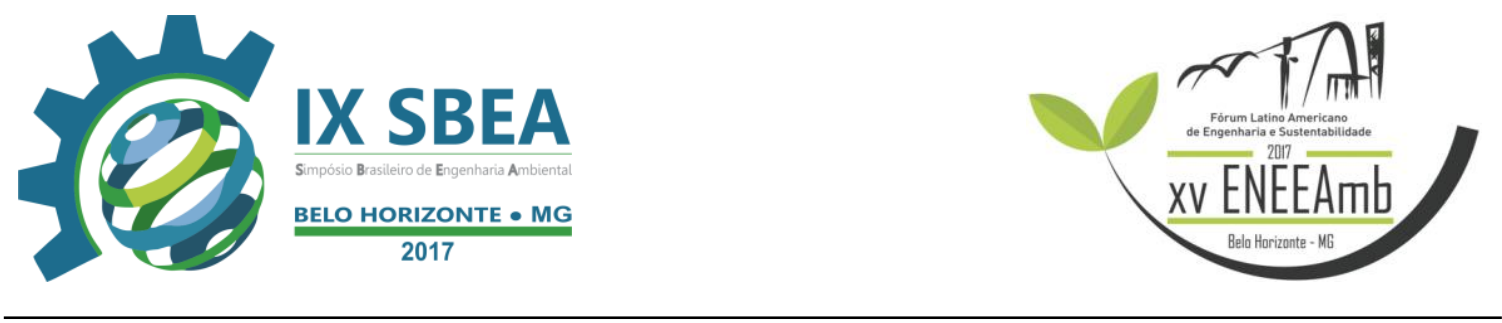

Souza et al. (2012), estabeleceram equações que ajudam a minimização dos erros em termos de definição das taxas pluviais para o estado do Pará. Para tanto, utilizaram séries históricas de dados pluviométricos de 74 cidades do Estado do Pará, inclusive Belém. Os ajustes matemáticos (equações de intensidade-duração-frequência) obtiveram coeficientes de determinação acima de 99.

De acordo com Flores (2012) as intensidades de precipitação estão entre 90 e $110 \mathrm{~mm} / \mathrm{h}$ na maioria dos municípios para chuvas de 30 minutos e tempo de retorno de 15 anos. Estes dados demonstram o enorme quantitativo pluvial disponível para o abastecimento com água da chuva nas cidades estudadas.

De posse do método estabelecido por Ghisi et al. (2006) a aplicação de Lima et al. (2011) e de Souza et al. (2012), evidenciam o enorme potencial de aproveitamento da água pluvial para abastecimento humano na Região.

\section{Componentes do sistema de captação e utilização de água de chuva}

É possível desenvolver diversos modelos de sistemas de captação de água de chuva, desde os mais simples até sistemas mais complexos. A norma brasileira NBR 15527/07 - Água de chuva - Aproveitamento de coberturas em áreas urbanas para fins não potáveis - determina que a concepção de qualquer projeto de sistemas de coleta e aproveitamento de águas pluviais seja desenvolvido atendendo aos requisitos da NBR 5626/98 - Instalação Predial de Água Fria- e da NBR 10844/89 - Instalações Prediais de Águas Pluviais.

A metodologia básica para projeto de sistemas de coleta, tratamento e uso de água pluvial envolve as seguintes etapas, de acordo com o Manual de Conservação e Reúso da Água em Edificações (ANA, FIESP \& SindusCon-SP, 2005):

- $\quad$ Determinação da precipitação média local (mm/mês);

- $\quad$ Determinação da área de coleta;

- $\quad$ Determinação do coeficiente de escoamento superficial;

- $\quad$ Caracterização da qualidade da água pluvial,

- $\quad$ Projeto do reservatório de descarte;

- $\quad$ Projeto do reservatório de armazenamento;

- $\quad$ Identificação dos usos da água (demanda e qualidade); 


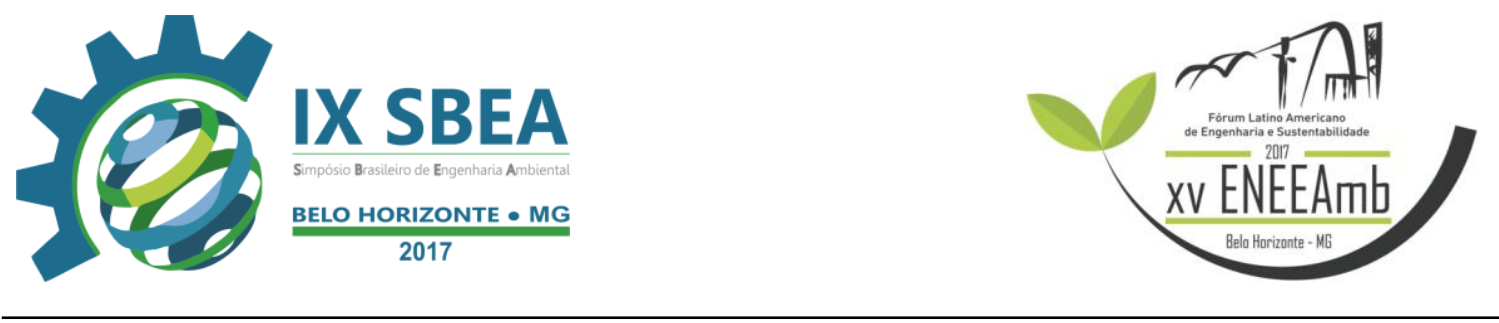

- $\quad$ Estabelecimento do sistema de tratamento necessário;

- $\quad$ Projeto dos sistemas complementares (grades, filtros, tubulações etc.).

\section{Métodos de dimensionamento de reservatórios para água de chuva}

Existem diversos métodos utilizados para efetuar o cálculo do dimensionamento de reservatórios de água de chuva. A NBR 15527/07 cita em seu apêndice alguns modelos que podem ser utilizados para tal finalidade:

a) Método de Rippl;

b) Método da Simulação;

c) Método Azevedo Neto;

d) Método Prático Alemão;

e) Método Prático Inglês;

f) Método Prático Australiano.

Geralmente esses métodos seguem uma mesma sistemática utilizando dados de: séries históricas de chuva, demanda a ser atendida, a área de captação, o coeficiente de escoamento superficial e a eficiência requerida para o sistema como dados de entrada e obtêm como resultado os volumes de armazenamento dos reservatórios necessários. (THOMAS \& MCGEEVER, 1997 apud ANNECCHINI, 2005).

Os reservatórios dimensionados por qualquer método devem atender a NBR 12217/94 que trata de Projeto de reservatório de distribuição de água para abastecimento público, devendo ser considerados no projeto o extravasor, dispositivo de esgotamento, cobertura, inspeção, ventilação e segurança.

$\mathrm{O}$ volume dos reservatórios deve ser dimensionado com base em critérios técnicos, econômicos e ambientais, levando em conta as boas práticas da engenharia, devendo ser limpos e desinfectados com solução de hipoclorito de sódio, ao menos uma vez por ano, conforme a ABNT 5626.

\section{CONCLUSÕES/RECOMENDAÇÕES}

A implantação e utilização deste tipo de sistemas podem proporcionar diversos benefícios ao meio ambiente como: conservação de água, educação ambiental, redução do escoamento superficial, a consequente redução da carga nos sistemas urbanos de 


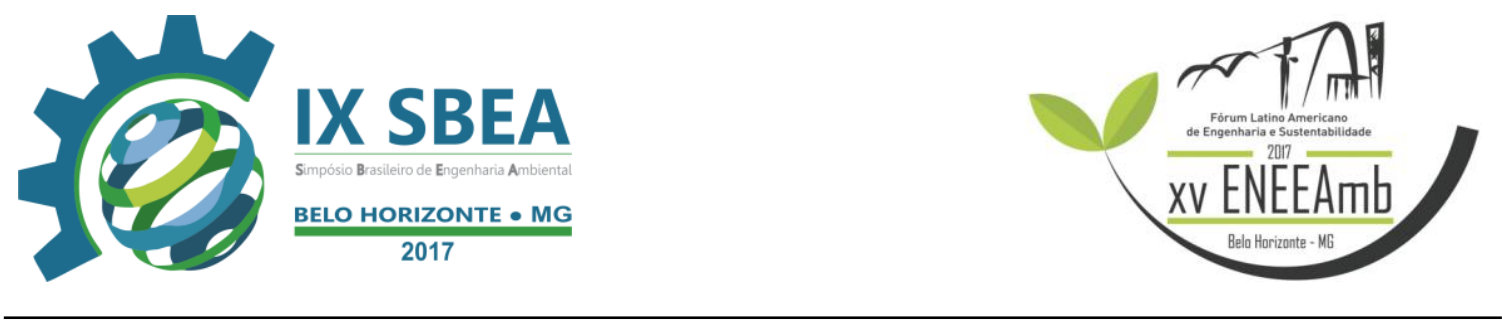

coleta de águas pluviais, o amortecimento dos picos de enchentes, contribuindo para a redução de inundações.

Além dos benefícios ao meio ambiente, existem também as vantagens econômicas propiciadas pela implantação destes sistemas, pois toda a água captada, e após recebido o tratamento adequado se for o caso, pode ser utilizada para múltiplas finalidades, ajudando assim a minimizar a falta de água, sem falar do consumo indevido de água tratada a qual possui um custo relativamente elevado. Entre os usos que as águas pluviais poderão ser aproveitadas estão: irrigação de solos, lavagem de veículos, fontes de água, reabastecimento de bacias sanitárias, limpeza de pisos, entre outros.

Sendo assim, a avaliação econômica dos projetos de aproveitamento de água pluvial é considerada bastante positiva, podendo reduzir, significativamente, os valores mensais das contas de água.

\section{REFERÊNCIAS BIBLIOGRÁFICAS}

AGÊNCIA NACIONAL DE ÁGUAS (Brasil). Conjuntura dos recursos hídricos: Informe 2015 / Agência Nacional de Águas. - Brasília: ANA, 2015.

ANA, FIESP \& SINCUSCON- SP. Conservação e reuso de água em edificações. São Paulo: Prol Editora Gráfica. 2005. 152 p.

ANNECCHINI, K.P.V. Aproveitamento da água da chuva pra fins não potáveis na cidade de Vitória (ES). 2005. 150f. Dissertação (Mestrado em Engenharia Ambiental) - Universidade Federal do Espírito Santo, Vitória, 2005.

ASSOCIAÇÃO BRASILEIRA DE NORMAS TÉCNICAS. NBR 15527: Água de chuva: aproveitamento de coberturas em áreas urbanas para fins não potáveis: requisitos. Rio de Janeiro, 2007. 8p. 
ASSOCIAÇÃO BRASILEIRA DE NORMAS TÉCNICAS. NBR 12217: Projeto de reservatório de distribuição de água para abastecimento público. Rio de Janeiro, 1994. $4 \mathrm{p}$.

ASSOCIAÇÃO BRASILEIRA DE NORMAS TÉCNICAS. NBR 5626: Instalação predial de água fria. Rio de Janeiro, 1998. 41p.

ASSOCIAÇÃO BRASILEIRA DE NORMAS TÉCNICAS. NBR 10844: Instalações prediais de águas pluviais: procedimento. Rio de Janeiro, 1989. 13p.

BRASIL. Lei no 9.433, de 8 de Janeiro de 1997. Institui a Política Nacional de Recursos Hídricos, cria o Sistema Nacional de Gerenciamento de Recursos Hídricos, regulamenta o inciso XIX do art. 21 da Constituição Federal, e altera o art. $1^{\circ}$ da Lei $n^{\circ} 8.001$, de 13 de março de 1990, que modificou a Lei $\mathrm{n}^{\circ}$ 7.990, de 28 de dezembro de 1989.

BRASIL. Lei ${ }^{\circ}$ 6.381, de 25 de julho de 2001. Dispõe Sobre a Política Estadual de Recursos Hídricos, instituí o Sistema de Gerenciamento de Recursos Hídricos e dá outras providências.

FLORES, R.A.; MENDES, R.L.R.; OLIVEIRA, D.R.C.; COSTA, T.C.D.; VELOSO, N.S.L.; Potencial de captação de água de chuva para abastecimento: o caso da cidade de Belém (PA, Brasil). Estudos Tecnológicos em Engenharia, vol. 8, N. 2, p. 69-80, jul/dez 2012

GHISI, E. A Influência da Precipitação Pluviométrica, Área de Captação, Número de Moradores e Demandas de Água Potável e Pluvial no Dimensionamento de Reservatórios para Fins de Aproveitamento de Água Pluvial em Residências Unifamiliares. Monografia apresentada ao Departamento de Engenharia Civil da Universidade Federal de Santa Catarina como parte dos requisitos para participação no Concurso Público do Edital Nº 026/DDPP/2006.Florianópolis, 2006. 
INSTITUTO BRASILEIRO DE GEOGRAFIA E ESTATÍSTICA (IBGE). 2016. Censo

Demográfico. Disponível em: http://www.ibge.gov.br. Acesso em: 27/04/2017.

LIMA, J.A.; DAMBROS, M.V.R.; ANTONIO, M.A.P.M. de; JANSEN, J.G.; MARCHETTO, M. 2011. Potencial da economia de água potável pelo uso de água pluvial: análise de 40 cidades da Amazônia. Revista de Engenharia Sanitária e Ambiental, 2011.

MINAS GERAIS. Aproveitamento de água pluvial. Disponível em: < http://feam.br/images/stories/2016/PRODUCAO_SUSTENTAVEL/GUIASTECNICOSAMBIENTAIS/CARTILHA_AGUA_DA_CHUVA_INTRANET.pdf >. Acesso em: 25 de abril de 2017.

OLIVEIRA, T. D,; CHRISTMANN, S. S.; PIEREZAN, J. B.; Aproveitamento, captação e (re) uso de águas pluviais na arquitetura. Revista GEDECON. V. 2, n3, 01$15,2014$.

OLIVEIRA. M. H. C. Aproveitamento da água de chuva. Monografia de Pós Graduação, Universidade Tecnológica Federal do Paraná, Paraná, 2014.

SOUZA, R.O.R.M.; SCARAMUSSA, P.H.M.; AMARAL, M.A.C.M.; PEREIRA NETO, J.A.; PANTOJA, A.V.; SADECK, L.W.R. 2012. Equações de chuvas intensas para o Estado do Pará. Revista de Engenharia Agrícola e Ambiental, 2012.

VASCONCELOS, Leonardo F.; FERREIRA, Osmar M. Captação de água de chuva para o uso domiciliar: estudo de caso, 2007. Disponível em < http://www.pucgoias.edu.br/ucg/prope/cpgss/ArquivosUpload/36/file/CAPTA\%C3\%87 \%C3\%83O\%20DE\%20\%C3\%81GUA\%20DE\%20CHUVA\%20PARA\%20USO\%20D OMICILIAR.pdf > . Acesso em 07 de abril de 2017 .. 